\title{
DA MATERIALIDADE DOS CORPOS À MATERIALIDADE DO CRIME. A MATERIALIZAÇÃO DA PORNOGRAFIA INFANTIL EM INVESTIGAÇÕES POLICIAIS
}

\author{
Laura Lowenkron
}

\begin{abstract}
Eu proporia no lugar destas concepções de construção um retorno à noção de matéria, não como local ou superfície, mas como um processo de materialização que se estabiliza através do tempo para produzir o efeito de fronteira, de permanência, de superfície que chamamos matéria. Creio que o fato de que a matéria esteja sempre materializada deve ser entendido em relação aos efeitos produtivos e, na realidade, materializadores do poder regulador no sentido foucaultiano (Butler 2002:28, tradução minha).
\end{abstract}

Este artigo é baseado em uma pesquisa etnográfica realizada na Superintendência Regional do Departamento de Polícia Federal no Rio de Janeiro e, mais especificamente, em um núcleo especializado responsável por investigar crimes relacionados à circulação de "pornografia infantil" na internet — popularmente conhecidos como "crimes de pedofilia". ${ }^{1}$ Partindo da premissa de que a noção de "pornografia infantil" não deve ser tomada como autoevidente, ${ }^{2}$ neste texto procuro discutir e mostrar como os corpos que servem de suporte para a construção da materialidade dos chamados "crimes de pedofilia" ou "pornografia infantil na internet" ${ }^{3}$ são produzidos por um processo de materialização governado por normas reguladoras, como sugere a filósofa norte-americana Judith Butler (2002:39).

A autora refere-se à materialização dos corpos sexuados, argumentando que a diferença sexual nunca é simplesmente uma função de diferenças materiais que não estejam de algum modo marcadas e formadas por práticas discursivas. No entanto, ela ressalta:

Afirmar que as diferenças sexuais são indissociáveis das demarcações discursivas não é o mesmo que dizer que o discurso causa a diferença sexual. A categoria "sexo" é, desde o começo, normativa; é o que Foucault denominou 


\begin{abstract}
"ideal regulatório". Nesse sentido, o "sexo" não apenas funciona como norma, mas também é parte de uma prática reguladora que produz os corpos que governa, isto é, cuja força reguladora se manifesta como uma espécie de poder produtivo, poder de produzir - demarcar, circunscrever, diferenciar - os corpos que controla (Butler 2002:17-18, tradução minha).
\end{abstract}

Apesar de as formulações de Butler $(2002,2003)$ serem particularmente sugestivas para a análise do meu material etnográfico, é importante destacar que esta perspectiva está inserida em um movimento intelectual mais amplo, no âmbito dos chamados estudos de gênero, de desessencialização da diferença sexual e da própria divisão, supostamente universal, entre natureza e cultura. Como mostra Moore (1994), se em um primeiro momento a distinção entre sexo e gênero foi crucial para o desenvolvimento da Antropologia Social, pois permitiu desnaturalizar as categoriais "homens" e "mulheres" antes concebidas como pré-sociais, ${ }^{4}$ por outro lado, essa separação fez com que durante muito tempo a categoria sexo e a diferença sexual não fossem devidamente examinadas, visto que eram associadas à ordem dos atributos físicos do corpo e reconhecidas como cruciais para a reprodução biológica das populações. ${ }^{5}$

É preciso notar, contudo, que corpos, processos fisiológicos e partes corporais não têm significado fora do entendimento cultural que se faz deles, como aponta Moore (1994:816). Nas últimas décadas generalizou-se no campo de estudos de gênero e sexualidade a concepção de que a ideia de um sexo pré-social é produto do discurso biomédico. Esse entendimento foi profundamente influenciado pela sugestão foucaultiana de que o sexo seria um efeito do dispositivo da sexualidade. O autor afirma que a noção de sexo permitiu agrupar nesta unidade artificial elementos anatômicos, funções biológicas, condutas, sensações e prazeres, bem como fazer funcionar esta unidade fictícia como princípio causal, significante único e significado universal (Foucault 1988:144-145).

De maneira análoga aos efeitos produzidos na disciplina pela separação entre as categorias sexo (natureza) e gênero (cultura), sugiro que a distinção entre maturidade fisiológica (puberdade) e social ${ }^{6}$ tenha sido bastante útil para o desenvolvimento da Antropologia, mas levou à essencialização da primeira. Ainda que as chamadas "ciências duras" reconheçam cada vez mais a influência de fatores socioambientais sobre as funções fisiológicas do organismo, a puberdade foi predominantemente pensada na Antropologia Social como a matéria bruta sobre a qual se inscrevem as variadas interpretações culturais a respeito das mudanças físicas corporais que dariam origem a diferentes arranjos sociais. 
Assim como foi sugerido em relação às categorias sexo e gênero, entendo que a própria separação entre maturidade sexual fisiológica e social pode ser pensada como uma divisão socialmente construída. Dessa maneira, proponho que as mesmas operações analíticas realizadas em relação ao sexo podem e devem ser feitas em relação à diferenciação e ao reconhecimento dos corpos em referência a um constructo nativo da ciência ocidental moderna sobre um processo supostamente universal de maturação sexual fisiológica, denominado "puberdade", o qual também pode ser entendido como efeito das mesmas normas reguladoras que governam a materialização do sexo: o dispositivo da sexualidade.

Partindo do pressuposto de que não existe uma realidade corporal prédiscursiva sobre a qual se realiza a construção social, sugiro que seja possível se apropriar da formulação de Butler (2002) em relação à performatividade do "sexo"7 para pensar também sobre a performatividade dos atributos físicos de idade. Procuro evidenciar a pertinência desta apropriação ao longo da descrição etnográfica das análises policiais que definem as imagens que podem ser classificadas como "pornográficas" e que demarcam, circunscrevem e diferenciam os corpos que podem ser identificados como "infantis". O objetivo é mostrar como o olhar investigativo constitui a materialidade do crime e a materialidade dos corpos reciprocamente, produzindo assim os corpos que governa.

Não pretendo sugerir com isso que os corpos materializados nas cenas de "pornografia infantil" possam ser pensados simplesmente como efeito da atividade policial de materialização do crime. Evidentemente, o olhar policial sobre essas imagens constitui apenas uma perspectiva situada, como qualquer outra, sobre um processo que resulta da estilização repetida de atos corporais diante de múltiplos olhares - o olho do fotógrafo, o olho do "pedófilo-espectador", o olho do policial, o olho do juiz, o olho da antropóloga - que se articulam de forma a estabilizar a materialidade dos corpos, ainda que possam atribuir-lhe valores distintos: comercial, erótico, criminal e epistemológico.

No entanto, considero que o saber-poder prático dos agentes da Polícia Federal, exercido predominantemente por meio do olhar especializado do investigador, oferece uma perspectiva heuristicamente privilegiada e socialmente aceitável para a realização de uma etnografia que pretende compreender o processo de materialização dos corpos na "pornografia infantil" e a sua materialização enquanto instrumento de acusação criminal. Vejamos agora como essas formulações conceituais abstratas ganham materialidade nas investigações policiais que pude observar e das quais participei ao longo da minha pesquisa de campo. 


\section{Materialização da pornografia infantil em investigações policiais}

Frequentemente os agentes da Polícia Federal do núcleo especializado no qual a etnografia foi realizada chamavam-me para acompanhar o processo de análise de sites pornográficos denunciados, em grande parte, por usuários anônimos de internet. Essa interação cotidiana com os dois agentes desse núcleo - que chamarei aqui de APF Richard e APF Alfredo - possibilitoume entender como eles filtravam e selecionavam as denúncias recebidas. Primeiramente, observei que havia uma hierarquia dos denunciantes e que alguns não podiam jamais ser ignorados. Por mais que a denúncia pareça infértil, quando ela é encaminhada pelo Ministério Público Federal, é exigida uma apuração e uma resposta que tem prazo determinado. Portanto, responder a esses expedientes era uma das prioridades dos agentes do núcleo, apesar de muitas vezes eles considerarem essas apurações como "perda de tempo". É o caso, por exemplo, das inúmeras denúncias sobre portais de pornografia na internet, formados por um conjunto de sites interconectados que ficam hospedados em servidores estrangeiros.

Nesses portais, cada página (URL) exibe fotos pornográficas dos gêneros mais variados e cada imagem funciona como um link interligando infinitamente diferentes páginas ou portais de pornografia, algumas vezes direcionando a sites comerciais cujo acesso depende de pagamento com cartão de crédito - e, por isso, os policiais não podem entrar para analisar o conteúdo. Os links são dinâmicos, isto é, a cada vez que o usuário clica em uma imagem ele é direcionado a uma página diferente. Em poucos casos há fortes indícios de que esses sites de acesso livre e gratuito contenham alguma foto de menores de idade. Portanto, em geral, os agentes propõem arquivamento das denúncias que se referem a esses portais. Caso seja localizada alguma imagem de "pornografia infantil", eles sugerem o encaminhamento da denúncia à Interpol, uma vez que se trata de site estrangeiro. Existem também alguns denunciantes que se transformam em verdadeiros colaboradores, segundo o APF Richard:

Tem alguns colaboradores que, quando vejo email dessa pessoa, eu já leio com certeza, que geralmente é "coisa boa", entre aspas, coisa ruim. É crime configurado mesmo. Uma mulher fez disso uma cruzada pessoal dela, ela não faz outra coisa senão ficar varrendo internet e ficar mandando pra gente. Então, quando é email dela, a gente já olha com mais carinho.

Outro critério fundamental para decidir se a apuração de uma denúncia será ou não levada adiante consiste na verificação da materialidade. Para 
isso, é preciso checar se a página de internet denunciada ainda está no ar. Se estiver, é necessário verificar se existe um "fato típico" (previsto na lei criminal), ou seja, se a imagem (foto ou vídeo) é ou não pornográfica e se pode ou não ser identificada a participação de menores de 18 anos na cena. Vale destacar que de acordo com o artigo 241-E do Estatuto da Criança e do Adolescente:

Para efeitos dos crimes previstos nesta Lei, a expressão "cenas de sexo explícito ou pornográficas" compreende qualquer situação que envolva criança ou adolescente em atividades sexuais explícitas, reais ou simuladas, ou exibição dos órgãos genitais de uma criança ou adolescente para fins primordialmente sexuais.

Observa-se que, apesar de o legislador ter procurado precisar a definição de "pornografia infantil", o texto legal ainda deixa brechas para interpretação no que diz respeito aos fins da imagem, a qual é sempre contextual, situacional e relacional. Certa vez, por exemplo, apareceram em um inquérito fotos de crianças nuas junto com adultos nus, em um contexto de "naturismo", de modo que não foi configurado o fim sexual da imagem e, por isso, na análise pericial, ela não foi considerada "pornográfica". Assim, com o intuito de eliminar quaisquer resquícios de ambiguidade, os agentes priorizam as imagens de "abuso mesmo", que pode ser tanto o ato sexual envolvendo crianças quanto uma performance com caráter explicitamente sexual, como é definido na fala do APF Richard:

A gente trabalha muito com a foto do abuso mesmo. Porque você pega uma criança numa foto "artística", o cara pode desqualificar no futuro dizendo que acha bonito o nu dos 7 anos ou 10 anos. Ainda mais se tiver nu de homens e mulheres de todas as idades, mas sem abuso sexual... Há pais idiotas que fazem isso, tiram fotos dos filhos pelados e acham uma maravilha. [...] Mas se você pega uma foto de uma criança, não há abuso, mas uma foto ginecológica, o negócio já começou... Está havendo um abuso. Uma foto artística? Ah, uma menininha sem roupa, mas com um chapéu, com uma toquinha... Tudo bem, ainda pode ser considerado... Agora, quando pega uma menina, bota ela de quatro, bota braço pra trás, bota ela em posição de frango assado, aí já está caracterizado abuso.

Outro elemento fundamental para configurar a materialidade do crime é a caracterização da menoridade da(s) pessoa(s) envolvida(s) na cena pornográfica. É importante destacar que, apesar de o texto da lei se basear na 
idade cronológica para a definição do delito (menores de 18 anos), é muito raro identificar as crianças e os adolescentes que atuam nessas cenas a partir da análise das imagens, o que seria necessário para verificar com precisão a condição de menoridade. As fotografias e os vídeos disseminam-se muito rapidamente pela rede mundial de computadores e, uma vez na internet, uma imagem antiga tende a voltar ou a continuar a ser divulgada a partir de qualquer ponto do planeta, ainda que seja possível obrigar um site específico a retirá-la do ar em um dado momento. É comum que as mesmas imagens apareçam em diferentes investigações policiais nos mais diversos países e que registros pornográficos antigos continuem circulando na internet durante muito tempo. Desse modo, é praticamente impossível localizar o ponto zero de divulgação e muito difícil encontrar o produtor das imagens e, consequentemente, as crianças e os adolescentes que nelas aparecem.

Isto não significa que os policiais sejam insensíveis ou não se importem com as crianças, seus sofrimentos e paradeiro. Ficam inclusive extremamente satisfeitos e particularmente orgulhosos de sua nobre função de "proteger a sociedade" quando conseguem localizar alguma "vítima" e prender o "abusador", já que, em meio aos múltiplos "alvos" atingidos pelas megaoperações contra usuários e difusores de "pornografia infantil", algumas vezes encontram "indícios" de que o consumidor e/ou disseminador é também um "abusador" de crianças e produtor desse tipo de material.

O que importa destacar aqui é que na maioria dos casos não se identificam as crianças e os adolescentes que aparecem nas imagens, de maneira que, na prática, para a configuração da materialidade do crime de "pornografia infantil", não basta ser menor, é preciso parecer que o é sem a menor sombra de dúvida. Nesse sentido, a dimensão performativa da idade é particularmente evidente e eficaz neste contexto, na medida em que se observa uma centralidade da estilização repetida dos corpos e dos atos no interior de uma estrutura reguladora encarnada e exercida pelo olhar policial, que governa a construção e a substancialização das categorias etárias. ${ }^{8}$ Passo, então, a analisar o processo de eleição das marcas que importam para a caracterização da menoridade. ${ }^{9}$

Segundo o APF Alfredo, eles utilizam um critério "objetivo" para definir a menoridade. Essa "objetividade" é baseada na sensibilidade estética dos agentes, que discutem entre si sobre as imagens observadas. Segundo Alfredo, quando há dúvida ou controvérsia é porque a menoridade é "subjetiva", o que não é suficiente como prova judicial. Isto mostra que a menoridade, para ser constituída como "real" ou "objetiva", não pode apresentar variações segundo o ponto de vista, pois deve estar indubitavelmente inscrita na materialidade dos corpos. Em alguns casos não há qualquer margem de 
dúvida, afirmam os policiais. Pergunto como se estabelece isto. Eles dizem que é o "senso comum". "Bebê ou criança de 2, 3, 5 anos. Não há dúvida", afirma o APF Richard.

No entanto, há casos em que as fronteiras entre fantasia e realidade, lícito e ilícito, normal e anormal são bastante tênues, de modo que, apesar de ser crime, é difícil configurar materialidade no caso de imagens pornográficas que envolvem meninos e meninas situados na zona cinzenta da "adolescência". ${ }^{10}$ Os agentes explicam que existem muitos sites pornográficos na internet nos quais a menoridade, principalmente a feminina, é simulada, visto que o corpo teen (adolescente) e a performance infantil são elementos valorizados no mercado do erotismo enquanto "fantasia sexual masculina", ainda que não exclusivamente. ${ }^{11} \mathrm{Com}$ frequência as denúncias encaminhadas à Polícia Federal referem-se a esse gênero pornográfico teen, que está dentro dos limites da legalidade e do aceitável, como explica o APF Richard:

Em tese, se $20 \%$ procedem, $80 \%$ não caracterizam [pornografia infantil]. Mas tem uma zona muito cinzenta e a gente só pode trabalhar numa certa... Eu garanto que, às vezes, nós deixamos passar alguma coisa que seja. Não dá pra provar que a criança é menor, então, não dá. Porque o cara olha "teen" e acha que é adolescente. Só que "teen" vai de 13 até 19. E os sites pegam isso. E todo mundo acha que "teen" é adolescente, mas eles pegam de 18 e 19. São "teen". Você pega um adolescente de 19 anos tabuinha, faz uma depilação geral, bota ela carequinha, bota um tênis e uma "maria Chiquinha"... Vai botando todos os padrões e ela vai parecendo uma menina de 15, 14. O cara quer acreditar que ela seja menor de idade. [...] Não tenho percentual, mas a maior parte é descartável.

A fala do policial revela como a estilização dos corpos que tem como efeito a aparência de menoridade nas cenas classificadas pelos agentes do núcleo como "pornografia infantil falsa" ou "simulada"12 é resultado de uma combinação complexa de atributos físicos mais ou menos manipulados, gestos, roupas, adereços e percepções. De maneira similar à performance drag descrita por Butler enquanto modelo privilegiado para compreender as dramatizações de gênero (2002), essa espécie de paródia da "pornografia infantil" representada pelo gênero pornográfico teen acaba por desestabilizar as próprias distinções entre natural e artificial e, no caso, entre legal e ilegal.

Identificadas pelos denunciantes como representação de corpos infantis e descartadas pelos policiais como não configuração de materialidade, essas imagens iluminam o caráter performativo da construção das corporalidades fisiologicamente imaturas ao mimetizarem os elementos significantes mediante os quais a chamada "pornografia infantil verdadeira" se estabelece. 
Se, por um lado, as dramatizações de corpos impúberes encenadas na "pornografia infantil simulada" permitem compreender por que olhares distintos podem produzir corporalidades diferenciadas em relação a marcadores etários, por outro, o caráter escorregadio e fluido da classificação dessas cenas não se ajusta bem à exigência de precisão na cronologização legal dos corpos para a configuração da materialidade do crime.

Por isso, a menoridade constituída em face do olhar policial deve ser mais rigorosa que as demais, não podendo variar de acordo com o contexto, os adereços, os ângulos e os pontos de vista. Deve ser baseada em um critério "objetivo", como definiu um dos agentes da Polícia Federal. Nesse sentido, sugiro que a característica distintiva do processo de fabricação e estabilização das corporalidades ou, como preferi denominar neste contexto etnográfico, de materialização dos corpos por meio das análises policiais das imagens, é ter como efeito a substancialização de marcadores etários e a separação e a hierarquização de corporalidades "falsas" e "verdadeiras" - o que requer, evidentemente, uma boa margem de segurança entre a idade aparente e o critério cronológico de menoridade estabelecido pela lei.

Vejamos como esse critério policial "objetivo" de definição da menoridade se atualiza em situações concretas de análise de imagens denunciadas. Sento-me ao lado do APF Alfredo para analisar uma "denúncia anônima" enviada ao serviço de Disque Denúncia da Secretaria Estadual de Segurança Pública, que fora encaminhada à Delegacia de Repressão a Crimes de Informática (DRCI) da Polícia Civil e depois redirecionada à Polícia Federal por se tratar de um site hospedado no exterior.

No título do documento consta o "assunto": "crimes contra criança e adolescente/ corrupção de menores/ crimes contra a liberdade sexual/ atentado violento ao pudor". Logo depois vem o "Relato": "Relata que no site ' $\mathrm{y}$ ' podem ser vistas várias fotos de crianças com idades entre 10 e 12 anos mantendo relações sexuais com adultos, acrescenta que há várias fotos de meninas nuas, amarradas, sendo violentadas e pede que seja averiguado". As fotos foram impressas pela Polícia Civil e anexadas ao documento. A "Informação" da Polícia Civil diz:

Pesquisando o site " $\mathrm{y}$ " da internet foi possível constatar que foram encontradas fotos de jovens menores de idade, aparentemente, em cenas obscenas ou pornográficas, conforme cópia impressa e juntada. O domínio do site está registrado para os Estados Unidos da América, conforme cópia impressa e juntada. O IP de hospedagem do domínio está registrado para os Estados Unidos da América, conforme cópia impressa e juntada. Desta forma, não possuindo jurisdição sobre o crime de pedofilia cometido em outro país, sugiro, SMJ [salve melhor 
juízo], a remessa do presente procedimento à Polícia Federal para informar as autoridades competentes.

É o que cabe informar.

Em razão da matéria, a denúncia foi encaminhada a este núcleo especializado da Polícia Federal para apuração preliminar. Analisando o site, o APF Alfredo apresenta-o como um típico caso de "perda de tempo". Na primeira página, impressa na denúncia, aparecem cenas de meninas que aparentam ser menores. Mas, ao clicar para abrir mais fotos - que, por sua vez, direcionam o usuário a outros sites interligados àquela página - ele mostra que aquelas que à primeira vista pareciam ser menores não parecem mais desta forma nas imagens seguintes. A maioria das fotos retrata meninas bem jovens, com corpos magros, seios pequenos, poucas curvas, pelo pubiano ralo ou depilado, usando acessórios e encenando performances infantis que chamei de estilo Lolita, isto é, inocentes, porém provocantes. Nos títulos das fotos aparecem palavras como "young", "teen", "tinny", "virgins".

Segundo o agente, sites como este contemplam a diversidade de fantasias eróticas dos seus usuários, mas querem estar dentro dos limites da legalidade. Estão também, como vimos, dentro dos padrões de pornografia consumida e apreciada de acordo com os critérios de sensibilidade estética associados a homens heterossexuais "normais". O agente explica que essas imagens são frequentemente denunciadas porque podem confundir o olhar do espectador comum, isto é, enganar os seus sentidos, levando-o a tomar a "fantasia" como se fosse "realidade", acreditando ser "real" uma menoridade que é apenas "ilusória", "simulada".

Entretanto, por meio de um exame minucioso, o olhar experiente do policial consegue identificar a diferença entre a menoridade "simulada" e os corpos que são inquestionavelmente "infantis", apesar de os agentes reconhecerem que nem sempre é possível ter certeza se as/os jovens são "adolescentes" de 15 ou 16 anos ou se têm um pouco mais de 18 anos. Na dúvida não se dá prosseguimento à investigação. "Para se gerar um inquérito sem ter provas de que as imagens retratam menores é preciso que a idade aparente seja inquestionável", ensina o APF Alfredo. É o que ele denomina de critério "objetivo" para definir menoridade. Em seguida, ele escreve a seguinte "Informação" sugerindo o arquivamento do caso. A peça é assinada pelos dois agentes.

\section{Senhor delegado,}

Trata-se de denúncia que versa sobre suposta difusão de material contendo pornografia infantil através da internet. O sítio " $\mathrm{y}$ " estaria divulgando material 
impróprio na rede mundial, com a participação de crianças com idades entre 10 e 12 anos, mantendo, inclusive, relações sexuais com adultos. Vale dizer que o referido sítio apresenta vasto conteúdo pornográfico, todavia não foi logrado êxito na identificação de qualquer indício relacionado com a pornografia infantil. Esta conclusão foi obtida após cuidadosa análise de todas as modelos expostas no sítio supracitado, sendo certo que, apesar de a primeira fotografia de cada modelo procurar convencer o observador de que se trata de pornografia infantil, verificando-se as demais fotos da mesma modelo, esta impressão sofre alteração, convencendo o observador de que não se trata de pornografia infantil, apenas de uma indução apelativa em relação à menoridade das modelos, que pode ser verificada na sequência das fotos.

Das medidas:

Pelo exposto, apresento à apreciação de Vossa Senhoria, as seguintes sugestões:

1. O arquivamento da denúncia em epígrafe, tendo em vista que as imagens com conteúdo relacionado com a pedofilia não foram identificadas.

É a informação.

Mas, afinal, como os investigadores conseguem diferenciar a "pornografia infantil" "real" da "simulada" enquanto os denunciantes estavam convencidos de que as mesmas imagens retratavam crianças entre 10 e 12 anos? Como distinguir esses corpos aparentemente "impúberes" daqueles que são dotados dos atributos físicos necessários para serem caracterizados pelos policiais como menoridade "objetiva"? Para isso é preciso atentar para os pormenores que escapam aos "olhos leigos" dos denunciantes e mesmo ao olhar profissional do fotógrafo que procura dissimular a idade da modelo os "copistas" ou "falsificadores" de menoridade. O olhar detetivesco dos agentes segue a lógica do paradigma indiciário. Ao propor este conceito, Ginzburg (1989) faz referência ao método desenvolvido pelo médico italiano Giovanni Morelli para atribuição de autoria de quadros antigos por meio da análise de indícios que possibilitavam distinguir os originais das cópias:

Para tanto, porém (dizia Morelli), é preciso não se basear, como normalmente se faz, em características mais vistosas, portanto mais facilmente imitáveis, dos quadros [...]. Pelo contrário, é necessário examinar os pormenores mais negligenciáveis, e menos influenciados pelas características da escola a que o pintor pertencia: os lóbulos das orelhas, as unhas, as formas dos dedos das mãos e dos pés. Dessa maneira, Morelli descobriu, e escrupulosamente catalogou, [...] traços presentes nos originais, mas não nas cópias (Ginzburg 1989:144). 
O autor aproxima o método de Morelli das técnicas detetivescas de Sherlock Holmes e da psicanalítica de Sigmund Freud: "nos três casos, pistas talvez infinitesimais permitem captar uma realidade mais profunda, de outra forma inatingível. Pistas: mais precisamente, sintomas (no caso de Freud), indícios (no caso de Sherlock Holmes), signos pictóricos (no caso de Morelli)" (Ginzburg 1989:150). Ancorada neste mesmo modelo epistemológico, a atenção dos agentes da Polícia Federal desse núcleo especializado orienta-se, neste primeiro estágio da investigação, para os indícios corporais que permitem identificar marcadores etários que servem para configurar a materialidade do crime.

Assim como Morelli fazia para identificar os verdadeiros autores dos quadros, os agentes se baseiam em elementos bastante peculiares para detectar os sinais de menoridade que, no contexto das imagens de "pornografia infantil", constituem o indício de um crime e são associados ao sintoma de um transtorno psicológico. Ao invés de examinar simplesmente os caracteres mais vistosos e evidentes que separam os corpos "sexualmente maduros" dos "pré-púberes" — como o porte da(o) modelo, o tamanho dos seios e a presença ou não de pelos pubianos, que justamente faziam com que os observadores "leigos" acreditassem que aquelas imagens poderiam ser classificadas como "pornografia infantil" — eles atentam para outros detalhes mais negligenciáveis, tais como a proporção entre o tamanho das pernas, dos braços e de outras partes do corpo em relação ao tronco, a forma da cabeça, além da performance.

Entretanto, seria difícil e pouco profícuo tentar catalogar os traços que definiriam a menoridade segundo os critérios utilizados pelos agentes de maneira a codificar esse saber prático, pois suas regras escapariam a qualquer tentativa rígida de formalização. Por mais que exista um esforço por parte do órgão central da Polícia Federal, em Brasília, de oferecer treinamentos de tempos em tempos voltados para a uniformização dos procedimentos investigativos, da interpretação da lei e das técnicas de análise de imagens, "nesse tipo de conhecimento entram em jogo (diz-se normalmente) elementos imponderáveis: faro, golpe de vista, intuição" (Ginzburg 1989:179).

Certa vez o APF Alfredo me perguntou: "você sabe qual a diferença do trabalho do delegado para o do agente?". Diante da minha expressão de curiosidade e interesse, ele explicou: 'o agente pode colocar na 'Informação' as suas impressões. É um documento mais informal, mais subjetivo. O delegado está preocupado com o enquadramento em 'fatos típicos'. É mais formal e mais objetivo". Essa informalidade é justamente o que define a atividade dos agentes como um saber prático que só pode ser compreendido a partir da análise do ofício investigativo policial em ação. Sendo assim, a melhor 
maneira de apresentar como os corpos infantis são materializados nas cenas pornográficas examinadas pelos agentes do núcleo no qual a pesquisa foi realizada é por meio da descrição de algumas situações etnográficas nas quais eles configuram ou não a materialidade do crime.

O APF Richard analisa uma denúncia encaminhada pelo MPF à qual ele precisa responder em um prazo de 30 dias. Originalmente, a denúncia anônima havia sido encaminhada para o e-mail do Disque Denúncia com o link do site e o seguinte texto: "No site, encontra-se um monstruoso arquivo de fotos que são de enjoar qualquer cidadão por causa de seu conteúdo pedófilo". A Procuradoria da República direcionou a "notícia crime" para apuração da Polícia Federal por entender que havia "indícios" de "pornografia infantil".

O endereço denunciado é um portal pornográfico com fotos de meninas aparentemente muito jovens. Entretanto, na avaliação do APF Richard, não há "indícios" suficientes para configurar materialidade de que aquelas jovens são inquestionavelmente menores, como ele registra na "Informação": "o sítio apresenta já nas páginas iniciais, de acesso livre, farto material pornográfico, mostrando várias mulheres jovens em poses e atos de cunho sexual, mas em nenhum caso é possível afirmar sem sombra de dúvida que se trata de menores de idade". Ao me mostrar o conteúdo da página, Richard explica: "algumas têm cara de criança e corpo de mulher. Outras têm rosto de mulher e corpo de criança". Ele só considera ser criança se reunir as duas coisas, mas isso ele não escreve na "Informação".

Alguns dos sites observados apresentam certas áreas como "ilegais". É comum nessa parte do site encontrar legendas de fotos ou vídeos como "Young school girls suck and get fucked by father", que seria uma sugestão de "pedofilia" e "incesto". Segundo os agentes, isto é comercialmente atrativo, ainda que esses sites não aparentem ter conteúdo ilegal, ou seja, imagens de pornografia envolvendo menores de idade. Esses títulos costumam aparecer nas cenas nas quais corpos jovens são manipulados para simular menoridade. Também é comum encontrar nessas áreas dos sites pornográficos cenas que simulam estupro, violência, dor, desigualdades (velho com jovem, grande com pequeno etc.).

Vale notar que os agentes ficam desorientados ao se depararem com fotografias de meninas orientais que aparentam ser menores de idade. Afirmam que as "japas" são entendidas como uma categoria à parte, enquanto corpos impossíveis de categorizar pelos critérios ocidentais comuns de sensibilidade em relação à idade, pois, segundo eles, "elas não têm seios, nem formas (curvas) e nem pelos", isto é, não possuem os atributos considerados necessários para a identificação de marcadores corporais que definem o es- 
tágio de maturidade sexual fisiológica. Este fato revela como a tendência de apagar traços individuais de um corpo é diretamente proporcional à distância étnica do observador. Nos termos de Ginzburg (1989:164), "o conhecimento individualizante é sempre antropocêntrico, etnocêntrico".

O gênero do analista de imagens - que, neste núcleo especializado da Polícia Federal, é predominantemente masculino - também parece influenciar na avaliação das cenas. Ao observar uma foto de um garoto que aparenta ser um adolescente mantendo intercurso com uma mulher adulta, cuja legenda dizia "time to lose virginity", o APF parece se identificar com o ideal de masculinidade representado, pois alerta que é preciso observar se o menino é menor, o que é mais facilmente negligenciado, a menos que seja uma cena homossexual. "Porque, em tese, ele é vítima também, apesar de ele não se entender como tal", nota o agente. Por meio desse comentário, o agente sugere a hipótese de que a dupla moral sexual pode levar à subnotificação de imagens de "pornografia infantil" de casais heterossexuais nas quais o menino é o polo mais jovem.

Esta observação permite propor que existe uma inflexão diferenciada no processo de materialização dos corpos em relação aos marcadores etários (ou, ao menos, à relevância destes para a configuração da "violência sexual") de acordo com o gênero dos atores, isto é, segundo a posição de passividade (feminino) ou atividade (masculino) na cena pornográfica. Nesse sentido, é possível sugerir que a "violência sexual" é constituída não apenas pelas relações interetárias, mas também de gênero e, ao mesmo tempo, constrói gênero, já que os critérios de sensibilidade que definem essa violência enquanto relação de subordinação/objetificação são orientados pelo mesmo princípio ordenador generificado, que prescreve posições binárias e predefinidas de masculinidade/atividade e feminilidade/passividade no exercício da sexualidade.

Tal proposição permite compreender ainda como as percepções acerca das imagens pornográficas e das relações sexuais intergeracionais envolvendo menores de idade são atravessadas por concepções hegemônicas a respeito das relações entre gênero, sexualidade e violência. Como a sexualidade da mulher é associada quase sempre a um lugar de passividade, ela é facilmente identificada como "vítima", mas dificilmente vista como "agressora". Isto explica também por que o "menino" só costuma ser efetivamente entendido como "abusado" quando é feminilizado em uma cena erótica homossexual.

Uma das poucas vezes em que vi uma cena pornográfica na qual uma mulher participava de um ato entendido indubitavelmente como "abuso sexual infantil" foi em um vídeo antigo, considerado particularmente forte pelos agentes, e no qual uma senhora de cabelos grisalhos faz sexo oral 
em uma criança em torno de 5 anos, vestida de "Chapeuzinho Vermelho". Em seguida, a menina se senta no colo de um homem, também de idade avançada, que penetra a criança. Como de costume, o rosto do homem não aparece. Nesse vídeo, a figura da "abusadora" é desfeminilizada pelo envelhecimento e por praticar um ato sexual homossexual com uma menina de "tenra idade".

Ainda no que se refere ao processo de materialização dos corpos infantis, é importante notar que, como propõe Goffman (1985:74), "ser uma determinada espécie de pessoa [...] não consiste meramente em possuir os atributos necessários, mas também em manter os padrões de conduta e aparência que o grupo social do indivíduo associa a ela". Por isso, principalmente nos vídeos, a aparência de "discernimento", "desenvoltura" e "prazer" na performance sexual também é levada em conta para a descaracterização da "menoridade" e da "violência". Analisando junto com o APF Alfredo uma denúncia, achei, em função do rosto e do corpo da menina, que ela fosse menor. Ele inicialmente discordou, argumentando que ela parecia estar compreendendo o que estava acontecendo, sabia como agir na situação e também estaria aproveitando.

Era um vídeo "amador"/"caseiro" de sete minutos, em baixa resolução, que mostrava uma menina mantendo relação sexual com três jovens simultaneamente. A denúncia foi encaminhada para a Polícia Federal brasileira porque, apesar de o vídeo estar hospedado em um site estrangeiro, era possível identificar que a suposta menor usava uma camiseta de uma escola pública nacional e os atores falavam em português. A cena pornográfica começa com a menina fazendo sexo oral em dois garotos, ao mesmo tempo em que um terceiro rapaz mantém com ela intercurso sexual vaginal. A câmera focaliza o ato sexual e o rosto da menina aparece na cena porque eles filmam o sexo oral. Já os meninos são enquadrados predominantemente da cintura para baixo, com ênfase no pênis. "Claramente a garota sabe que tudo está sendo filmado, pois ela olha para a câmera", nota o agente. Em um dado momento, ela se levanta e sai correndo para um quarto. Dá para perceber que eles estão em uma casa ou um apartamento residencial. Depois eles voltam a fazer sexo em grupo.

O vídeo termina de carregar e podemos visualizar novamente a cena de modo contínuo e com som. Alfredo já estava escrevendo a "Informação" sobre a denúncia quando revê o filme completo e muda de ideia. Ele comenta que não acha mais que ela tenha tanto "discernimento". Apesar de não parecer nada "forçado", "violento", ela parece "meio perdida" e "ri nervoso". Além disso, pelo áudio, nota-se que ela tem uma voz infantil e que às vezes reclama que "está doendo". A partir disso, o agente reconsidera sua primeira impressão e escreve na "Informação" que a menina aparenta ser menor: 
Trata-se de denúncia que versa sobre suposta difusão de material contendo pornografia infantil através da internet.

O link "y" direciona para a apreciação de um vídeo pornográfico, que revela a prática de sexo entre três pessoas do sexo masculino com uma do sexo feminino. A maioridade dos participantes do referido vídeo pode apenas ser estimada, sendo certo que a qualidade do vídeo torna a tarefa ainda mais difícil, tendo em vista que foi obtida, provavelmente, através de geração via celular.

Por outro lado, em certos momentos durante a exibição do vídeo, é possível considerar que se trata de uma adolescente com idade inferior a 18 anos, sendo assediada, praticando sexo, possivelmente, para agradar seus amigos naquele momento [grifos meus].

Os participantes da gravação certamente são brasileiros, tendo em vista a camisa utilizada pela jovem, na qual pode ser observada a inscrição São Paulo, provavelmente referente a uma escola paulista, bem como acerca das conversas travadas pelos participantes.

O vídeo em questão foi colhido e armazenado em mídia tipo $\mathrm{CD}$, tendo em vista a preservação da materialidade. [...]

Na parte superior da tela do vídeo em questão pode ser observada a URL de outro sítio, "y", que provavelmente divulgou ou divulga o mesmo conteúdo.

Em análise nas páginas deste segundo sítio, nada foi identificado em relação à pornografia infantil atualmente, todavia será objeto de monitoramento a ser realizado por este Núcleo.

Conforme pesquisa, tanto o registrador, o administrador e o contato técnico do primeiro sítio apontam para o exterior.

\section{DAS MEDIDAS}

Pelo exposto, apresento à apreciação de Vossa Senhoria as seguintes sugestões:

1. O encaminhamento do expediente à INTERPOL, vez que o referido vídeo atualmente está sendo difundido pela internet através de um sítio com domínio, registrador, administrador e contato técnico localizados nos EUA, conforme pesquisa efetuada.

1. A consequente retirada do vídeo supracitado daquele sítio.

2. Verificação acerca de participação de brasileiros no feito.

É a informação.

Ao afirmar que a menina parece ser menor de 18 anos por estar se submetendo àquela situação não por prazer, mas para agradar os seus parceiros, a "Informação" mostra que os "indícios" de "menoridade" e de "violência" (sugerida na expressão "assédio"), portanto, de materialidade do crime, são baseados, neste caso, menos em atributos corporais e mais em determinados padrões de conduta de gênero e idade identificados na performance sexual. 
Como se pode perceber a partir do relato sobre a mudança de percepção do agente a respeito da menoridade da menina, não foi simplesmente (e nem preponderantemente) a idade aparente dos atores deste vídeo pornográfico, mas sim a encenação de um script de "inexperiência", "nervosismo", "submissão" e "dor" que ofereceu elementos que puderam ser associados pelo policial à sexualidade adolescente feminina.

É importante destacar que, em caso de dúvida quanto à menoridade das pessoas envolvidas na cena pornográfica, não se gera inquérito. Pergunto a um delegado se é o princípio do in dubio, pro reu que guia essa decisão. ${ }^{13}$ Ele diz que não, que este princípio é válido no processo judicial. Na fase da investigação é o contrário: in dubio, pro societate. ${ }^{14} \mathrm{O}$ delegado explica que este critério de seleção é baseado em uma decisão pragmática, em uma economia de tempo, que leva a priorizar as investigações que têm maior probabilidade de dar certo. Foi o mesmo motivo exposto pelos agentes. "Não adianta nada trabalhar e no final morrer na praia. Porque o perito vai dizer: não há como confirmar que a criança é efetivamente menor de idade. Então, a gente nem perde tempo", afirma o APF Richard.

Comentando sobre o que se leva em consideração ao analisar as imagens, o APF Alfredo diz: "o que importa, tanto para a polícia quanto para o Ministério Público, é o que o juiz vai achar". Ele considera que não vale perder tempo com uma investigação em que o "indício" será futuramente desqualificado. Isto revela como a expertise do olhar do agente se deve em grande parte à sua suposta capacidade de antecipar o olhar do juiz, ${ }^{15}$ já que a autoridade judicial é responsável por avaliar em última instância a validade dos "indícios" apurados pela investigação policial para determinar se estes são suficientes para dar início à próxima etapa (judicial) do processo de incriminação (Misse 2011) ${ }^{16}$ do "alvo".

Criar um procedimento, uma investigação, sem nenhum embasamento, a coisa acaba não tendo o resultado esperado. Se tiver alguma dúvida, mais à frente, no Judiciário, a coisa vai morrer. Então, tem que ser uma coisa explícita, que esteja ali realmente configurada. Você não pode criar como um indício alguma coisa que seja colocada em dúvida: eu acho que é, outra pessoa acha que não é. É perda de tempo.

Depois de configurada a materialidade nessa fase de apuração preliminar, o delegado instaura o inquérito policial, voltado para a identificação da autoria do crime. A partir da identificação do endereço físico de onde partiu a conexão do usuário suspeito são realizadas operações de "busca e apreensão" de computadores e mídias. Essas diligências constituem a etapa investigativa 
na qual os policiais vão às residências dos investigados (ou a uma empresa e outros locais públicos nos quais alguém se conectou à internet para praticar o crime) e literalmente trazem a materialidade para a delegacia. O objetivo é verificar se a imagem disponibilizada via internet pode ser encontrada no material apreendido e atribuída a determinado "alvo".

Ao analisar os arquivos gravados em um CD anexado ao "Laudo pericial" de um computador apreendido durante uma dessas operações, o APF Alfredo observa que há várias imagens que podem ser evidentemente classificadas como "pornografia infantil". Ele resolve, então, imprimir algumas para anexar à sua "Informação", na qual afirma ter encontrado material ilícito. Ele considera que, ao trazerem em si o peso da materialidade dos corpos impúberes envolvidos em cenas pornográficas, essas imagens possibilitam a qualquer um avaliar e verificar a menoridade dos atores envolvidos, bem como se indignar em face da materialidade e da monstruosidade do crime. Vale notar que a noção de monstruosidade não se restringe ao domínio do proibido ou do contra a lei, mas do ininteligível ou do contra a natureza, combinando, portanto, o impossível, o proibido e o inimaginável (Foucault 2002).

\section{Corpos (ab)errantes e sexualidades ininteligíveis}

Ao longo do artigo procurei mostrar como a materialização do crime de "pornografia infantil" produz corpos diferenciados não apenas em relação ao sexo, mas também - e neste caso primordialmente - a marcadores relativos à idade, substancializados a partir de um critério ordenador naturalizado (e naturalizante) que divide os corpos em estágios de maturidade sexual fisiológica ("púberes" e "impúberes", os quais se contrapõem implicitamente a "corpos sexualmente maduros"), que são frequentemente traduzidos em uma idade cronológica aparente ou convertidos em categorias que designam demarcações sociais relativas às fases da vida ("adulto", "adolescente" e "criança") e ao status jurídico ("maioridade" e "menoridade").

$\mathrm{Na}$ primeira parte do texto, propus uma apropriação e um deslocamento das operações analíticas realizadas em relação ao sexo/gênero para compreender a artificialidade da divisão entre maturidade sexual fisiológica (puberdade) e social e, de modo mais amplo, os processos de demarcação e identificação visual dos corpos quanto aos atributos físicos de idade. $\mathrm{Na}$ segunda parte, procurei evidenciar a pertinência etnográfica desse modelo analítico, mostrando como a "pornografia infantil" é definida diante do olhar detetivesco e das práticas investigativas policiais. Especial destaque foi conferido à descrição do exame de fotografias e vídeos pelos investiga- 
dores a fim de evidenciar o processo de eleição das marcas que importam para a caracterização do caráter pornográfico das cenas e, principalmente, da menoridade dos atores envolvidos.

Como foi possível observar, na configuração da materialidade desse crime por meio da análise das imagens, não é apenas e nem preponderantemente o conhecimento da lei que orienta a atuação dos agentes da Polícia Federal (ainda que este seja minimamente necessário para o ofício), mas sim o domínio de um saber prático tipicamente policial, isto é, "um conhecimento que só se aprende exercendo as funções policiais" (Lima 1994:74). Baseado no paradigma indiciário (Ginzburg 1989), o saber prático dos policiais consiste em uma arte de recolher "indícios" infinitesimais que são imperceptíveis aos olhos leigos e, a partir deles, distinguir as imagens de "pornografia infantil" "falsas" e "simuladas" das "verdadeiras", o que implica reconhecer os corpos inquestionavelmente "infantis" ou "impúberes". Para concluir este artigo, ensaio uma hipótese para explicar por que os indícios corporais da "puberdade" constituem um dos elementos centrais que servem para delimitar o caráter não apenas ilegal, mas acima de tudo monstruoso (Foucault 2002) e abjeto $^{17}$ (Butler 2002) das representações visuais classificadas como "pornografia infantil".

Se aceitarmos a provocação de Yanagisako e Collier (1987), segundo a qual é preciso explicar por que algumas características e atributos das pessoas são culturalmente reconhecidos e diferencialmente avaliados enquanto outros não, ${ }^{18}$ a questão que se pode colocar é: como compreender a centralidade da "puberdade" na identificação visual das classes de idade, em especial no contexto do comportamento sexual? Retomando a discussão teórica apresentada no início deste trabalho, sugiro que a divisão entre "corpos sexualmente maduros", "púberes" e "impúberes" deva ser entendida aqui não como um dado da natureza sobre o qual se impõe artificialmente uma cronologização dos corpos, mas como efeito sedimentado de um imperativo heterossexual e biologizante que governa a materialização dos corpos de acordo com a sua capacidade reprodutiva, ${ }^{19}$ seguindo, portanto, a mesma lógica ordenadora que produz também os corpos sexuados.

Em decorrência disso, proponho ainda que a "pornografia infantil", observada neste artigo através da perspectiva policial, ao apresentar "corpos impúberes" em interações sexuais com "corpos sexualmente maduros" e/ou em cenas construídas segundo uma estética do erotismo adulto, produz um corpo infantil poluído e poluidor porque fora do lugar (Douglas 1976). Tratase, portanto, de um processo de materialização de corporalidades infantis e sexualidades abjetas e monstruosas que desafiam os limites morais e estéticos do imaginável, do representável e do inteligível. 
Recebido em 06 de setembro de 2012

Aprovado em 05 de agosto de 2013

Laura Lowenkron é doutora em Antropologia Social e pesquisadora do Núcleo de Estudos de Gênero Pagu/Unicamp com bolsa FAPESP de pós-doutorado Email: <lauralowenkron@uol.com.br>

\section{Notas}

${ }^{1}$ Realizada de março de 2009 a dezembro de 2010, essa etnografia foi parte de uma investigação mais ampla, que deu origem à minha tese de doutorado (Lowenkron 2012), que visava compreender diferentes maneiras pelas quais as categorias "pedofilia" e "pornografia infantil" são socialmente construídas em meio a uma rede de saberes e poderes. A pesquisa na Polícia Federal tinha como objetivo estudar as práticas de conhecimento e os atos burocráticos por meio dos quais imagens eróticas são cotidianamente analisadas, classificadas e capturadas no âmbito de procedimentos administrativos estatais.

${ }^{2}$ Como advertem os psicólogos clínicos e forenses Taylor e Quayle, "quando analisamos o que se entende por pornografia infantil, começamos a encontrar incertezas e confusões. Os próprios termos 'criança' e 'pornografia' são controversos, com significados complexos e, por vezes, contraditórios" (Taylor \& Quayle 2003:2).

${ }^{3}$ Existe uma frequente confusão entre estes dois termos e conceitos nos discursos públicos (Lowenkron 2010, 2012). É importante destacar, contudo, que "pedofilia" não é crime, mas sim um transtorno mental definido pela psiquiatria (APA 2000; Trindade \& Breier 2010). Já as condutas de produzir, vender, divulgar e possuir ou armazenar "pornografia infantil" são criminalizadas na legislação brasileira. Ao mesmo tempo, os perigos associados a essas imagens derivam do fato de essas representações visuais serem imaginadas a partir de uma relação causal e mimética com fantasias e práticas sexuais correspondentes (Butler 2000), isto é, com a "pedofilia" e o "abuso sexual infantil". Como apontam diferentes estudiosos do tema (Tate 1990; Hacking 1992; Taylor \& Quayle 2003), além de retratar e implicar atos de "abuso sexual infantil" na sua produção, a "pornografia infantil" serve tanto como meio de troca e socialização entre pessoas que sentem atração sexual por crianças quanto como instrumento de validação, intensificação e normalização de suas formas de excitação e satisfação erótica. Pode ser utilizada também na intimidação das vítimas ou como ferramenta pedagógica para dessensibilizar e desinibir crianças para a prática de atos sexuais. 
${ }^{4}$ A ideia de que as categorias "homem" e "mulher" denotam mais constructos culturais do que tipos naturais e de que existe uma enorme variedade cultural nas definições de feminilidade e masculinidade foi apresentada há muito tempo na antropologia cultural norte-americana por Margaret Mead (1969) em Sexo e temperamento em três sociedades primitivas, publicado originalmente em 1935. Os estudos no campo da antropologia feminista nos anos 1970 desenvolveram essa noção mostrando que as diferenças biológicas entre os sexos não determinavam as construções de gênero (Moore 1994:814).

${ }^{5}$ Yanagisako e Collier (1987) estão entre as precursoras desse tipo de crítica ao argumentarem que as categorias analíticas de gênero e parentesco, tal como vinham sendo utilizadas nos estudos de antropologia social, eram incrustadas no modelo nativo ocidental de reprodução biológica da espécie humana e, por isso, a maior parte das análises acabava tomando como dadas diferenças que deveriam ser explicadas. Ao perceber que essas diferenças "fixas" entre os corpos não eram igualmente significativas em outras culturas, a antropologia precisou reformular e mesmo inverter o pressuposto de que o sexo era a base natural e universal que servia de suporte para as diferentes construções de gênero. Desde então, as discussões no campo da antropologia feminista voltaram-se para o questionamento da dicotomia entre sexo (natureza) e gênero (cultura), afirmando que ambos são socialmente construídos, um em relação ao outro.

${ }^{6}$ Essa separação foi destacada desde o início do século XX pelo antropólogo Van Gennep ao falar sobre os "ritos de iniciação" em seu livro Os ritos de passagem, publicado originalmente em 1909 (Gennep 1978).

${ }^{7}$ Nos termos da autora, "as normas reguladoras do 'sexo' atuam de uma maneira performativa para construir a materialidade dos corpos e, mais especificamente, para materializar o sexo do corpo, para materializar a diferença sexual a fim de consolidar o imperativo heterossexual" (Butler 2002:8, tradução minha).

${ }^{8}$ Inspiro-me aqui na conhecida formulação de Judith Butler a respeito da performatividade de gênero para destacar a dimensão performativa das categorias etárias. Nos termos da autora: "o gênero é a estilização repetida do corpo, um conjunto de atos repetidos no interior de uma estrutura reguladora altamente rígida, a qual se cristaliza no tempo para produzir a aparência de uma substância, de uma classe natural de ser" (Butler 2003:59).

${ }^{9}$ Segundo Vianna (1999), a menoridade deve ser entendida "não como um atributo relativo à idade, mas sim como instrumento hierarquizador de direitos" (:168). Menores são aquelas pessoas compreendidas como incapazes (ou relativamente incapazes) de responderem legalmente por seus atos de forma integral. Como destaca a autora (2002), enquanto os termos 'criança' e 'adolescente' remetem a representações referidas a indivíduos (ou semi-indivíduos) compreendidos em certa faixa etária, o termo 'menor' enfatiza a posição desses indivíduos em termos legais ou de autoridade, e evoca um tipo específico de regulação social, vindo do universo jurídico (Vianna 2002:6). 
10 "Ao visualizar uma imagem na ausência de qualquer informação sobre o indivíduo fotografado, tentar determinar uma idade pode se tornar uma questão de julgamento complexo. Embora não seja problemático decidir se a pessoa fotografada é uma criança quando é muito jovem, ao nos deslocarmos para a adolescência, tais decisões, quando baseadas em evidência visual, são muito mais difíceis de serem tomadas" (Taylor \& Quayle 2003:3).

${ }^{11}$ Esta afirmação do policial vai ao encontro dos relatos dos produtores da indústria pornô destacados no trabalho de Díaz-Benítez (2010:68): “mulher nova e, principalmente, menina com cara de ninfeta, isso com certeza vende". Nos termos da autora, "no pornô, existe uma grande valorização da juventude, uma extrema sexualização do corpo jovem" (Díaz-Benítez 2010:40). Ao mesmo tempo em que se pautam pela lógica do mercado, os profissionais entrevistados pela pesquisadora estabelecem limites entre o que consideram práticas sexuais "normais" ou aceitáveis e as espúrias. A "pedofilia" aparece justamente como a última fronteira moral no discurso de um diretor: "Eu faço muito filme de ninfeta, é o que o cliente mais procura. Mas eu não gravo nada que desperte a fantasia infantil. Uma coisa é você gravar uma garota vestida de colegial, uma adolescente tipo 19 anos, e outra coisa é você fazer filmes que liguem com algo infantil" (Díaz-Benítez 2010:108). A antropóloga informa ainda que, na indústria pornográfica brasileira, os atores maiores de idade com aparência adolescente são chamados de lolitos(as) ou ninfetos(as), enquanto internacionalmente são denominados teens ou teenagers.

${ }^{12}$ É importante destacar que o art. 241-C do Estatuto da Criança e do Adolescente (ECA), que criminaliza a "pornografia infantil simulada", não inclui esse tipo de simulação, mas tão somente a manipulação digital de imagens de crianças e adolescentes reais para a fabricação de foto ou videomontagem que simule a sua participação em cena pornográfica. Ou seja, o que é simulado neste caso é a própria cena pornográfica e não a menoridade do(a) performer. Para uma discussão a respeito da alteração legislativa que incluiu este artigo no ECA, ver Lowenkron (2012), capítulo 5.

${ }^{13} \mathrm{Na}$ dúvida, a favor do réu.

${ }^{14}$ Na dúvida, a favor da sociedade.

${ }^{15}$ Outros trabalhos antropológicos têm destacado a visão como um sentido proeminente no exercício de certas profissões, mostrando igualmente que a expertise desses olhares profissionais está associada à sua capacidade de conter virtualmente outros olhares. Em sua tese de doutorado sobre a relação entre mães e babás, Silveira (2011) cita uma frase particularmente reveladora nesse sentido dirigida a uma babá por sua patroa: "Na minha ausência os meus olhos são os seus olhos" (:92). Ao falar sobre o processo de seleção de atrizes e atores pornôs, Díaz-Benítez (2010) afirma que "os olhos dos recrutadores atuam como os olhos da indústria. Supõe-se que aquilo que eles enxergam nas pessoas, graças a um treinamento especializado da percepção, é também aquilo que vai obter respostas positivas do mercado. Quando o recrutador vê, ele já está antecipando o olhar do consumidor, já consegue vislumbrar em que tipo de representações pode incluir o dito sujeito e já estabelece um mapa de classificação" (:27). 
${ }^{16}$ A noção de incriminação é utilizada por Misse (2011) para se referir ao processo social de acusação do suposto autor dos eventos tratados como crimes.

17 “O abjeto designa aqui precisamente aquelas zonas 'invivíveis', 'inabitáveis' da vida social que, entretanto, estão densamente povoadas por quem não goza da hierarquia dos sujeitos, mas cuja condição de viver abaixo do signo do 'invivível' é necessária para circunscrever a esfera dos sujeitos" (Butler 2002:19-20, tradução minha).

${ }^{18}$ O caso apresentado por Fausto-Sterling (2002) sobre a corredora espanhola que foi reprovada no teste de sexo do Comitê Olímpico Internacional porque foi descoberto que ela possuía um cromossoma Y permite compreender de maneira particularmente clara o sentido dessa provocação. Apesar de ter um corpo feminino e sempre ter se visto e sido vista como mulher, pois ela era portadora de uma "síndrome de insensibilidade ao andrógeno" que impediu que desenvolvesse características masculinas, a atleta teve que lutar politicamente para que seu sexo voltasse a ser socialmente reconhecido como feminino. Ao mostrar como os parâmetros científicos para definir a "verdade do sexo" não são fixos, podendo ser ancorados ora nos órgãos genitais, ora nos cromossomos, a autora mostra que o que é selecionado enquanto significativo nos corpos varia historicamente e culturalmente, argumentando ainda, na mesma direção de Judith Butler, que nossas crenças sobre gênero definem o tipo de conhecimento que a ciência produz sobre o sexo.

${ }^{19}$ Esta ideia é inspirada na formulação de Judith Butler sobre o "sexo", segundo a qual este deve ser compreendido "não como um dado corporal sobre o qual se impõe artificialmente a construção de gênero, mas como uma norma cultural que governa a materialização dos corpos" (Butler 2002:19, tradução minha).

\section{Referências bibliográficas}

APA. 2000. Diagnostic and statistical manual of mental disorders - fourth edition - text revision. Arlington, Virginia: American Psychiatric Association.

BRASIL. 1990. Lei $\mathrm{n}^{\circ} 8.069$ - Estatuto da criança e do adolescente (ECA).

BUTLER, Judith. 2000. "The force of fantasy: feminism, Mapplethorpe and discursive excess". In: D. Cornell (ed.), Feminism and pornography. New York: Oxford University Press. pp. 487-508.
- 2002. Cuerpos que importam: sobre los limites materiales y discursivos del "sexo". Buenos Aires: Paidós. 2003. Problemas de gênero: feminismo e subversão da identidade. Tradução de R. Aguiar. Rio de Janeiro: Civilização Brasileira.

DÍAZ-BENÍTEZ, María Elvira. 2010. Nas redes do sexo: os bastidores do pornô brasileiro. Rio de Janeiro: Jorge Zahar. 
DOUGLAS, Mary. 1976. Pureza e perigo. São Paulo: Perspectiva.

FAUSTO-STERLING, Anne. 2002. "Dualismos em duelo". Cadernos Pagu, 17/18:9-79.

FOUCAULT, Michel. 1998. História da sexualidade I: a vontade de saber. Tradução de M.T.D.C. Albuquerque e J.A.G. Albuquerque. Rio de Janeiro: Edições Graal.

- 2002. Os anormais. Tradução de E. Brandão. São Paulo: Martins Fontes.

GENNEP, Arnald Van. 1978. Os ritos de passagem. Tradução de M. Ferreira. Petrópolis: Vozes.

GINZBURG, Carlo. 1989. "Sinais: raízes de um paradigma indiciário". In: (ed.), Mitos, emblemas, sinais: morfologia e história. São Paulo: Companhia das Letras. pp. 143-179.

GOFFMAN, Erving. 1985. A representação do eu na vida cotidiana. 3a. ed. Tradução de M.C.S. Raposo. Petrópolis: Vozes.

HACKING, Ian. 1992. "World-making by kind-making: child abuse for example". In: Mary Douglas \& David Hull (eds.), How classification works (Essays in honour of Nelson Goodman). Edinbugh: Edinbugh University Press. pp. 180-238.

LIMA, Roberto Kant de. 1994. A polícia da cidade do Rio de Janeiro. Rio de Janeiro: PMERJ.

LOWENKRON, Laura. 2010. "Abuso sexual infantil, exploração sexual de crianças, pedofilia: diferentes nomes, diferentes problemas?". Sexualidade, Saúde e Sociedade - Revista LatinoAmericana, 5:9-29. Disponível em: <http://www.e-publicacoes.uerj.br/ index.php/SexualidadSaludySociedad/article/view/394/726>. Acesso em: 11/05/2012.

. 2012. O monstro contemporâneo: a construção social da pedofilia em múl- tiplos planos. Tese de doutorado, PPGAS/Museu Nacional/UFRJ.

MEAD, Margaret. 1969. Sexo e temperamento em três sociedades primitivas. Tradução de R. Krausz. São Paulo: Perspectiva.

MISSE, Michel. 2011."O papel do inquérito policial no processo de incriminação no Brasil: algumas reflexões a partir de uma pesquisa". Revista Sociedade e Estado, 1(26): 15-27.

MOORE, Henrietta L. 1994. "Understanding sex and gender". In: T. Ingold (ed.), Companion encyclopedia of anthropology. London: Routledge. pp. 813-830.

SILVEIRA, Liane Maria Braga da. 2011. Como se fosse da família: a relação (in)tensa entre mães e babás. Tese de doutorado, PPGAS/Museu Nacional/UFRJ.

TATE, Tim. 1990. Child pornography: an investigation. London: Methuen.

TAYLOR, Max \& QUAYLE, Ethel. 2003. Child pornography: an internet crime. New York: Routledge.

TRINDADE, Jorge \& BREIER, Ricardo. 2010. Pedofilia: aspectos psicológicos e penais. Porto Alegre: Livraria do Advogado.

VIANNA, Adriana de Resende Barreto. 1999. O mal que se adivinha: polícia e menoridade no Rio de Janeiro. Rio de Janeiro: Arquivo Nacional. . 2002. Limites da menoridade: tutela, família e autoridade em julgamento. Tese de doutorado, PPGAS/Museu Nacional-UFRJ.

YANAGISAKO, Sylvia \& COLLIER, Jane. 1987. "Toward a unified analysis of gender and kinship". In: __. (eds.), Gender and kinship: essays toward an unified analysis. Stanford: Stanford University Press. pp. 14-50. 


\section{Resumo}

O objetivo do artigo é discutir como os corpos que servem de suporte para a construção da materialidade dos "crimes de pornografia infantil" são construídos/ materializados em face do olhar investigativo policial. Partindo do pressuposto de que não existe uma realidade corporal pré-discursiva sobre a qual se realiza a construção social, sugiro que as operações analíticas realizadas em relação ao sexo/ gênero podem ser utilizadas para compreender a artificialidade da divisão entre maturidade sexual fisiológica (puberdade) e social e, de modo mais amplo, o processo de diferenciação e identificação visual dos corpos quanto aos atributos físicos de idade. Essas formulações conceituais ganham materialidade na descrição etnográfica das análises policiais que definem as imagens que podem ser classificadas como "pornográficas" e os corpos que podem ser identificados como "infantis", explicitando como o olhar detetivesco constitui a materialidade do crime e a materialidade dos corpos reciprocamente, produzindo assim os corpos que governa.

Palavras-chave Pornografia infantil, Infância/menoridade, Corpo, Categorias etárias, Investigação policial.

\section{Abstract}

The aim of this article is to discuss how the bodies that support the construction of the materiality of "crimes of child pornography" are constructed/ materialized in the context of investigative police work. Assuming that there is no pre-discursive bodily reality upon which social construction is realized, I suggest that the analytical operations carried out in relation to sex/gender may be utilized to understand the artificiality of the division between physiological and social sexual maturity (puberty). In a wider sense, it can be used to interpret the process of visually differentiating and identifying bodies as physical attributes of age. These conceptual formulations gain materiality in the ethnographic description of the analyses carried out by police officers, who define the images that can be classified as being "pornographic" and the bodies which can be identified as "children", making explicit how a detective-eye reciprocally constitutes the materiality of crime and the materiality of bodies, thereby producing the bodies it governs.

Key words Child pornography, Childhood/minors, Body, Age categories, Police investigation. 